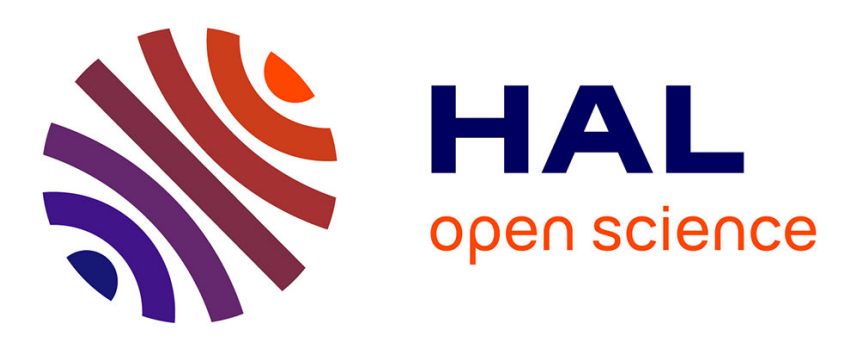

\title{
The use of cadmium telluride $\gamma$ spectrometers in monitoring activity deposited in nuclear power stations
}

L.T. Jones

\section{To cite this version:}

L.T. Jones. The use of cadmium telluride $\gamma$ spectrometers in monitoring activity deposited in nuclear power stations. Revue de Physique Appliquée, 1977, 12 (2), pp.379-384. 10.1051/rphysap:01977001202037900 . jpa-00244178

\section{HAL Id: jpa-00244178 https://hal.science/jpa-00244178}

Submitted on 1 Jan 1977

HAL is a multi-disciplinary open access archive for the deposit and dissemination of scientific research documents, whether they are published or not. The documents may come from teaching and research institutions in France or abroad, or from public or private research centers.
L'archive ouverte pluridisciplinaire HAL, est destinée au dépôt et à la diffusion de documents scientifiques de niveau recherche, publiés ou non, émanant des établissements d'enseignement et de recherche français ou étrangers, des laboratoires publics ou privés. 


\title{
THE USE OF CADMIUM TELLURIDE $\gamma$ SPECTROMETERS IN MONITORING ACTIVITY DEPOSITED IN NUCLEAR POWER STATIONS
}

\author{
L. T. JONES \\ Central Electricity Generating Board Berkeley Nuclear Laboratories Berkeley Gloucestershire, England
}

\begin{abstract}
Résumé. - La possibilité d'inspecter et de contrôler, voire de réparer ou remplacer des composants clefs d'un réacteur nucléaire est importante pour assurer la sécurité des centrales. En particulier, il est nécessaire de connaître les taux de dépôt ainsi que la composition des contaminants radioactifs qui s'accumulent dans ces zones. Comme il est souvent difficile de prélever des échantillons en vue de leur analyse en laboratoire, il serait commode, pour leur identification, d'employer la spectroscopie $\gamma$ directement sur place. Nous présentons ici les résultats de deux expériences entreprises auprès d'un réacteur. Dans une première expérience on compare les mérites respectifs des diodes $\mathrm{CdTe}$ et germanium H. P. dans des conditions d'emploi identiques. Dans le deuxième cas les mesures sont effectuées à $70^{\circ} \mathrm{C}$ sous un flux de radiations de $10 \mathrm{R} \mathrm{h}^{-1}$. La température de la diode CdTe est stabilisée à $20^{\circ} \mathrm{C}$ et l'ensemble électronique comporte un système anti-empilement de façon à pouvoir enregistrer des taux de comptage de $10^{5} \mathrm{~s}^{-1}$.

On a constaté que les paramètres du détecteur, généralement considérés comme essentiels, tels la résolution du compteur et son volume actif, ne sont pas nécessairement les facteurs déterminants dans les cas pratiques. Il apparaît, comme d'ailleurs pour les spectromètres Ge HP que le paramètre essentiel est le rapport pic/comptons.
\end{abstract}

\begin{abstract}
The ability to inspect and test key components and when necessary repair or replace them is a significant factor in the safety case submitted before consent is given for construction of a nuclear reactor. A knowledge of the probable rate of deposition and isotopic composition of radioactive contamination in these areas is necessary and since it is not always practicable to take samples away to the laboratory for analysis, direct gamma ray spectroscopy in the contaminated environment is sometimes used. The experience of direct monitoring with a Cadmium Telluride spectrometer in two such reactor situations is reported here.

In the first situation, a remotely cooled Intrinsic Germanium spectrometer was used in equivalent positions and spectra from both systems are presented. The relative merits of the two systems are discussed.

In the second situation, measurements were made in an environment at $70^{\circ} \mathrm{C}$ in radiation levels of $10 \mathrm{R} \mathrm{h}^{-1}$. An improvised cooling system was used to maintain the Cadmium Telluride at about $20^{\circ} \mathrm{C}$ and Pile-up Rejection was used to enable count rates of about $10^{5} \mathrm{~s}^{-1}$ to be handled.

It is noted that the usually quoted detector parameters, resolution and crystal volume, are not necessarily the most important in practical spectrometry of mixed isotopes. As with germanium detectors, the most useful parameter is probably the Peak-to-Compton ratio.
\end{abstract}

1. Introduction. At various stages of the design and construction of a nuclear power station, safety documents have to be presented to the licensing authorities, who also review the operating history and condition of the reactor at regular intervals throughout the life of the station. Of major concern is naturally the integrity of pressure components, shutdown mechanisms and cooling systems. These components of the reactor system must be capable of regular inspection and testing and if this can be achieved by man access rather than by remote viewing equipment and remote handling devices, this is generally preferred. When maintenance or repair is required man access is even more preferable although remote techniques are well advanced.
In areas where manual inspection and maintenance is required, radiation shields are provided to limit neutron activation to acceptable levels, however such shields may be effectively bypassed if radioactivity is transported by the reactor coolant. The activity may consist of fission products if failure of the fuel cladding exposes uranium to the coolant, activation products of other core components released by corrosion or abrasion, or even corrosion products from out of core components which may deposit in the core, become activated and subsequently be transported around the coolant circuit. Information on the transport of activity is valuable both at the design stage, when information from prototypes will indicate whether manual inspection and maintenance of parti- 
cular areas is feasible, and when the station is operating to give advance warning if the build up of longlived isotopes is greater than expected and to indicate suitable modifications to plant or operating procedures to reduce the problem.

Monitoring the deposition of activity by removal of samples for laboratory counting is often not satisfactory. If part of the coolant circuit surface is physically removed, loosely attached activity may be lost. If a sample is obtained by scraping a surface, activity which has been sintered onto the surface or which has diffused into the surface may not be sampled. Electrolytic methods sample the surface efficiently by removing the oxide layer from the surface but may thereby induce unacceptable corrosion. Consequently, there is an incentive to monitor the active deposits directly with a gamma spectrometer. This is the only way monitoring can be carried out while the reactor is operating and access to internal surfaces is not feasible.

Monitoring has principally been carried out using small intrinsic Ge spectrometers of about $0.5 \mathrm{~cm}^{3}$ with either conventional or remote cooling systems. Crystals of this size will count satisfactorily in radiation fields of up to $2 \mathrm{R} \mathrm{h}^{-1}$, which is about the maximum in which useful inspection or maintenance can be carried out and down to $10 \mathrm{mR} \mathrm{h}^{-1}$ if counting time is limited to one hour. CdTe detectors are now avalable at this size and offer the prospect of a more compact system for situations where detectors have to be inserted into confined spaces and of removing the cooling problems in inaccessible situations which would require remote cooling for a Ge detector or in high radiation areas where manual supplies to a conventional dewar would incur significant radiation exposure of personnel.

2. Operating conditions. - The conditions imposed when making power station measurements are usually far from ideal. The main electronics are normally sited in an outdoor mobile laboratory whose temperature variations often cause electronic drift. Connections from there to the detector and preamplifier may require 200 metre cable runs, passing welding sets and heavy electrical equipment and giving maximum opportunity for electrical pickup. Frequently, the operator positioning the detector is irradiated with the detector so there is a strong incentive to minimise the counting time by maximising the count rate in order to minimise personnel exposure. The electronics is therefore optimised for high count rates rather than best resolution.

As a consequence of these conditions, a Ge detector which is capable of $2.2 \mathrm{keV}$ resolution in the laboratory under ideal conditions may only achieve $4.5 \mathrm{keV}$ under power station conditions and this, rather than the laboratory performance, is the standard against which the performance of CdTe detectors should be judged.
3. CdTe with pulse shape discrimination (P. S. D.) A CdTe detector $\left({ }^{1}\right)$ was initially acquired for possible use in a specific high count rate situation and part of the detector evaluation was the use of the detector with a Pulse Pile-up Rejector. It was noticed that the detector resolution was critically dependent on the setting of the TRIM control of the Pile-up Rejector, and that a considerable improvement in resolution could be obtained compared with the normal spectrum. By using an abnormal setting of the control, this unit could be made to reject the more slowly rising pulses from the detector. The effect could not be exploited with the Pile-up Rejector since the optimum setting of the TRIM control was found to be energy dependent. Instead a commercial Pulse Shape Analyser was used to investigate the variation of detector performance with pulse rise time [1]. The variation of the ${ }^{137} \mathrm{Cs}$ spectrum with rise time is shown in figure1.

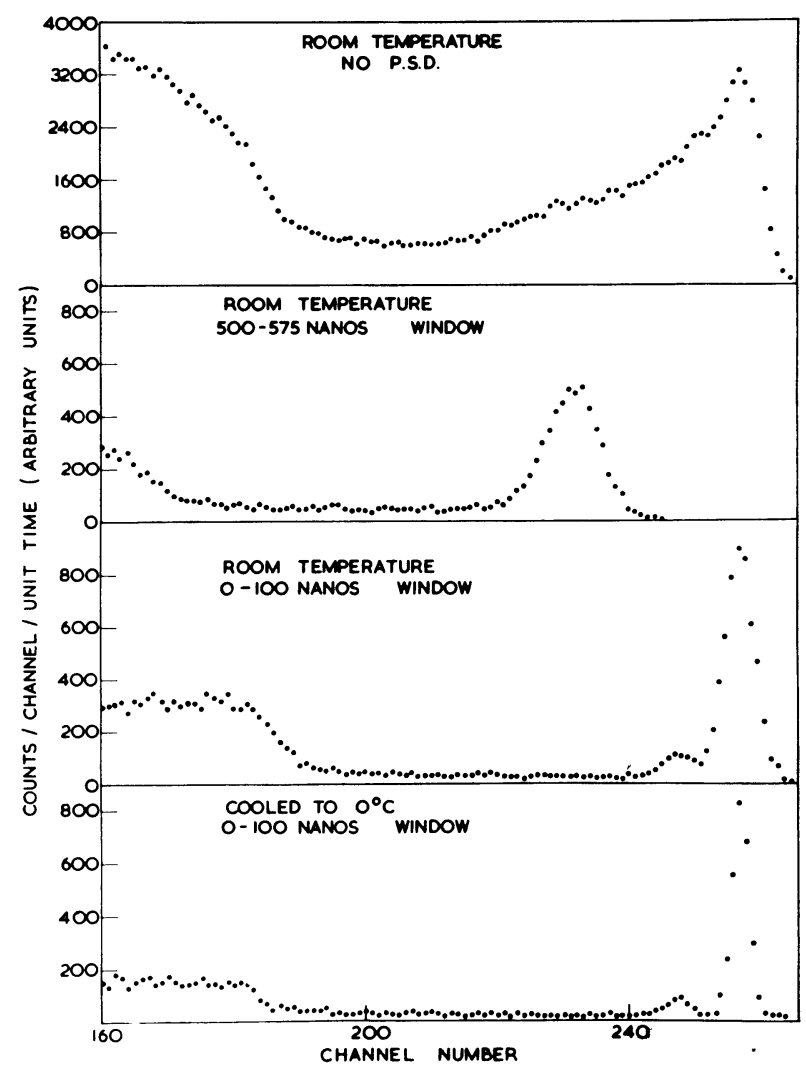

FIG. 1. - CdTe spectra from ${ }^{137} \mathrm{Cs}$ showing the effects of pulse-shape discrimination and detector cooling.

By counting only those pulses with a rise time of less than $100 \mathrm{~ns}$ it was possible to achieve a resolution for ${ }^{137} \mathrm{Cs}$ of $14 \mathrm{keV}$ at room temperature and $8 \mathrm{keV}$ at $0{ }^{\circ} \mathrm{C}$. A ${ }^{226} \mathrm{Ra}$ spectrum recorded at room temperature appears in figure 2 showing resolution varying from $13 \mathrm{keV}$ at $295 \mathrm{keV}$ to $17 \mathrm{keV}$ at $1.765 \mathrm{keV}$.

(1) From Tycho Laboratories INC. $30 \mathrm{~mm}^{3}$ of halogen doped CdTe with Platinum contacts. 


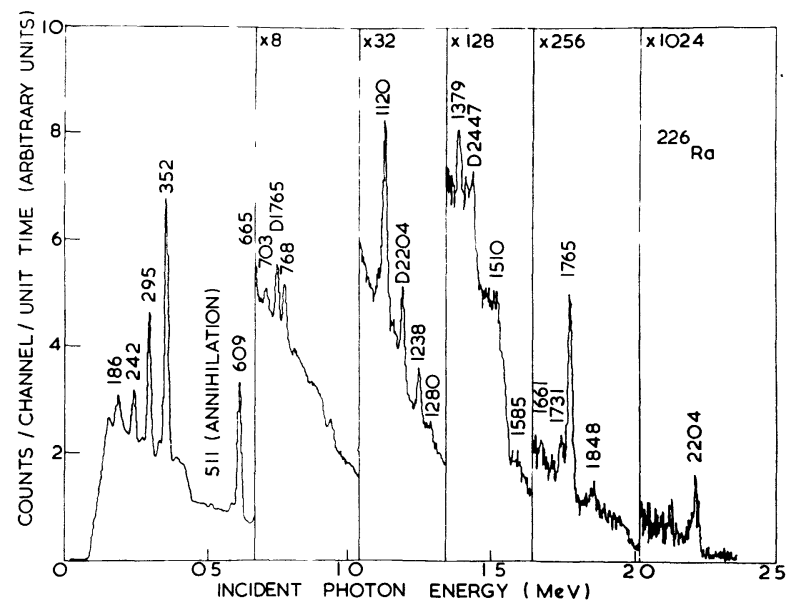

FIG. 2. - Room temperature $226 \mathrm{Ra}$ spectrum recorded with CdTe using pulse-shape discrimination.

In many ways the use of P. S. D. is undesirable in power station situations. It considerably complicates the setting-up of equipment. It reduces the detector efficiency by rejecting a large proportion of the pulses. When the physical arrangement of detector and preamplifier is changed, pulse rise times are altered and for a given rise-time acceptance window the system efficiency is changed. Any alteration in detector noise, due to temperature effects on leakage current for example, will not only alter the noise contribution to the photo-peak width, but may also affect the pulserise time measurement and change the rise-time acceptance window, affecting both photopeak width and system efficiency.

Despite these problems, P. S. D. has been used in all CdTe power station measurements the author has performed. Apart from the improvement in resolution there are three reasons for this :

(i) With P. S. D. the photopeaks are much more Gaussian than the normal CdTe spectrum. If a photopeak has significant low energy tailing, the peak area is easy to evaluate when there is no background under the peak, but in practical spectroscopy of mixed isotopes where most of the peaks are located on the rapidly rising Compton continuum from higher energy lines, such a tailed peak can look like a Compton Edge. Indeed the computer program SAMPO [2] when supplied with peak shape data for such a spectrum will automatically fit peaks to all the Comptorn Edges. The extraction of the photopeak area in these conditions is very difficult.

(ii) Although the P. S. D. system rejects about $90 \%$ of the photopeak area, only about half the peak height is lost and since the Compton Edge is also reduced by $90 \%$, the Peak to Compton ratio is substantially improved.

(iii) A characteristic of the spectra from all small detectors is a rapidly rising continuum at low energies. This is attributable to recoil electrons originating either in the detector or the surrounding material which lose only a part of their energy in the sensitive volume of the detector. From the geometry of $\mathrm{CdTe}$ detectors, usually a thin flat disc, the majority of these escaping electrons will have a large direction component parallel to the electric field. Since the shortest pulse rise-times occur with electrons moving at rightangles to the field close to the negative contact, P. S. D. preferentially rejects those events in which the electron enters or escapes from the detector and thereby reduces the low energy continuum.

These factors all increase the ability to identify and integrate low energy peaks against the background produced by higher energy photons, which is the principal problem in analysing a mixed spectrum.

As long as the charge collection time in $\mathrm{CdTe}$ detectors is comparable with carrier lifetimes and with the main amplifier time constant needed to give good test pulse resolution, P. S. D. provides a means of improving the resolution of any given detector and enables the user to optimise for his own application the balance of detector efficiency versus resolution and ease of spectrum analysis.

4. Reactor applications. - Two applications of $\mathrm{CdTe}$ detectors on reactors are presented, in both of which information was required on the distribution of activity along the axis of the exchangers. The physical layout of the first situation is shown in figure 3 .

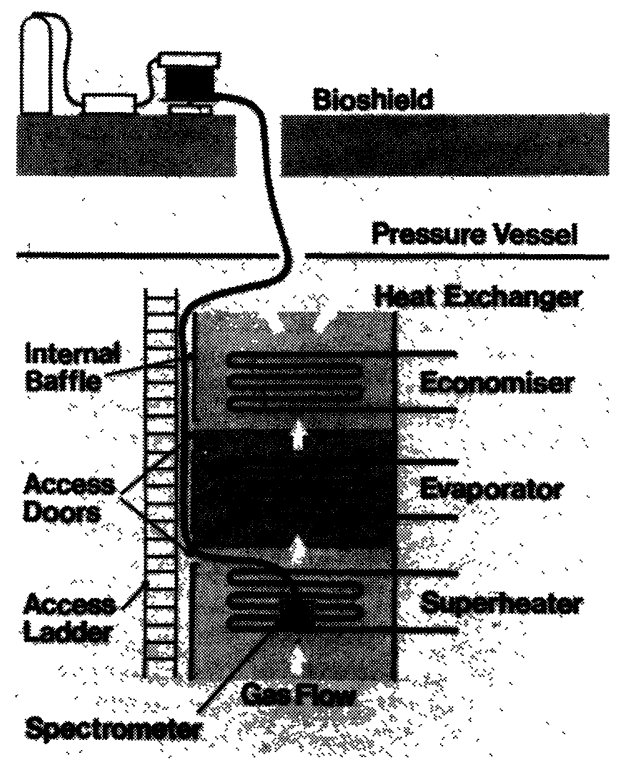

FIG. 3. - First reactor application. Physical arrangement.

In this application it was necessary to insert a spectrometer between the rows of tubes in each bank of the heat exchanger with nominal spacings between tubes of $27 \mathrm{~mm}$ in the superheater, $16 \mathrm{~mm}$ in the evaporator and $25 \mathrm{~mm}$ in the economiser. The respective heights of the banks were $4.2,4.5$ and $1.8 \mathrm{~m}$. Measurements were made using CdTe in all three banks of one 
heat exchanger and using a remotely cooled $\mathrm{Ge}$ detector in the superheater and economiser banks only of two other similar heat exchangers. The Ge cryostat was too large to permit access to the evaporator.

Spectra obtained with both CdTe and Ge detectors are shown in figure 4 . The two CdTe spectra with

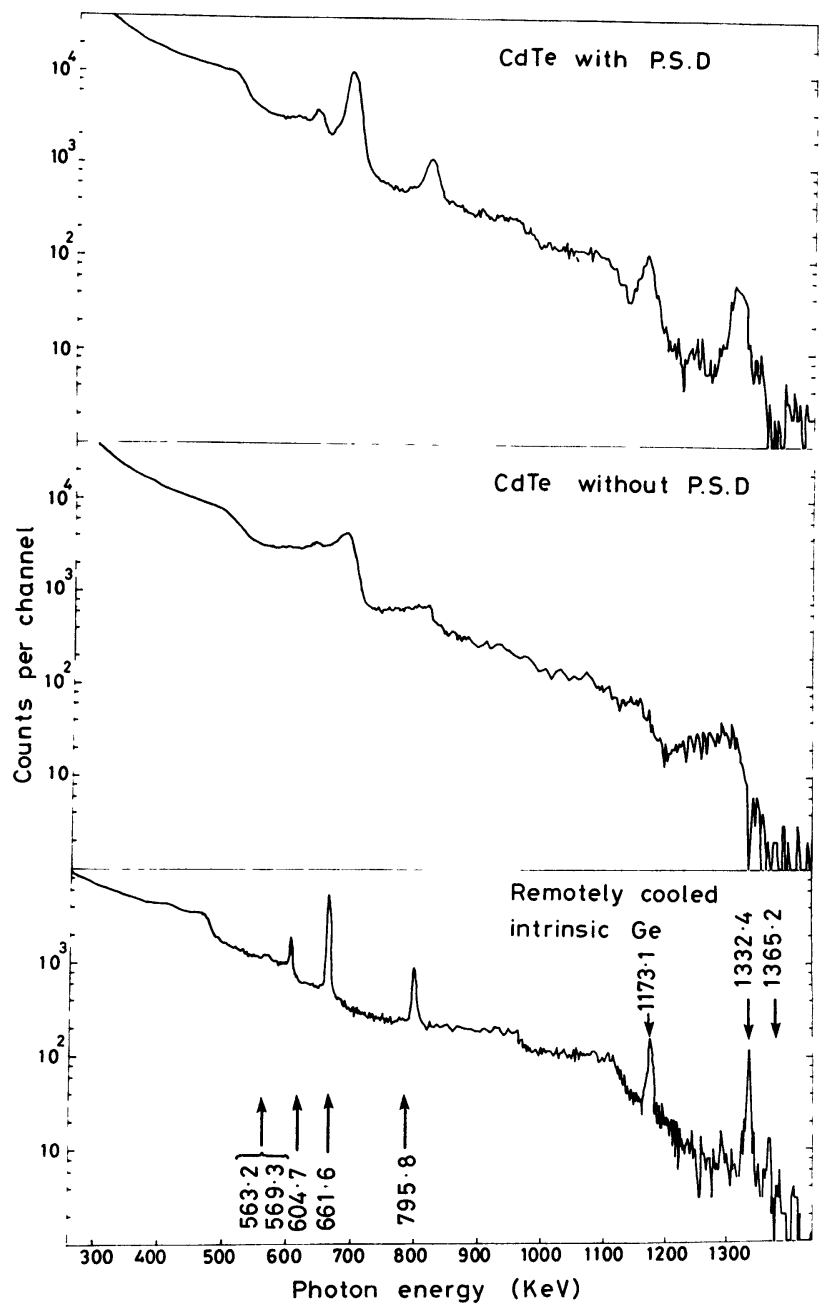

FIG. 4. - First reactor application. Typical spectra.

and without P. S. D. were taken at the same position, but the Ge spectrum was taken at the equivalent position in a different heat exchanger so that absolute levels may differ by a factor of two. The Ge spectrum shows resolution of about $4.4 \mathrm{keV}$ with a Peak to Compton ratio $(P / C)$ of about 1.0 while the $\mathrm{CdTe}$ has resolution of about $22 \mathrm{keV}$ with Peak to Compton of 0.5. The poor CdTe resolution, even with P. S. D., is attributable mainly to the long cables each side of the preamplifier. The block circuit is shown in figure 5.

The energy of the ${ }^{137} \mathrm{Cs}$ peak was consistently determined by Sampo to an accuracy of $1 \mathrm{keV}$ in a series of measurements lasting 16 hours. Errors in the ${ }^{60} \mathrm{Co}$ energy were about $3 \mathrm{keV}$, but this error represents only one channel when the photopeak area was

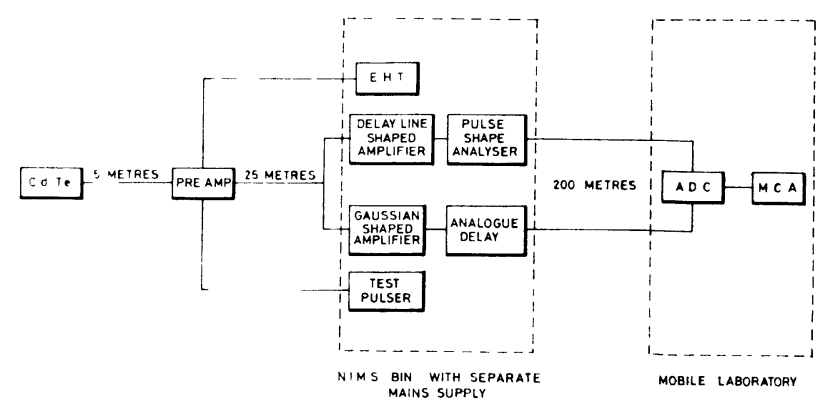

FIG. 5. - First reactor application. Block electronics.

less than 100 counts with only 10 to 20 counts in the peak channel.

Figure 6 shows the variation in surface activity, $S_{\mathrm{A}}$, along the axis of the heat exchanger. Apart from entrance and exit effects the deposition was expected to be exponential with each bank of the exchanger.

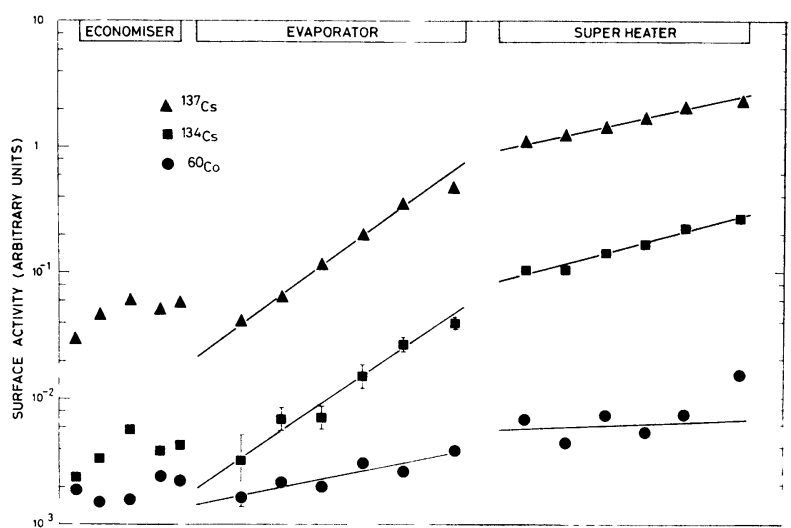

FIG. 6. - First reactor application. Axial variation of activity.

The solid lines shown are a linear regresssion fit to $\ln S_{\mathrm{A}}$ and for ${ }^{137} \mathrm{Cs}$ the measured points show a standard deviation of about $4 \%$ from the fitted line in the evaporator and superheater banks, in reasonable agreement with the estimated accuracy of from 1.5 to $6 \%$ on the individual measurements. For ${ }^{134} \mathrm{Cs}$ the exponents of the fitted lines differ from the ${ }^{137} \mathrm{Cs}$ values by about $20 \%$, but these differences are not significant because of the larger errors in the individual ${ }^{134} \mathrm{Cs}$ measurements, ranging from $5 \%$ at the inlet to the superheater, to $50 \%$ at the outlet of the evaporator. Errors in the ${ }^{60} \mathrm{Co}$ measurements are estimated to be about $30 \%$.

In the second reactor application the heat exchanger shown in figure 7 was much smaller and access to the heat exchanger tubes was not possible without mechanical dismantling. However, removal of the bypass valve and its drive mechanism gives access via the bypass duct with a minimum aperture of about $10 \mathrm{~cm}$ to the axis of the heat exchanger. 


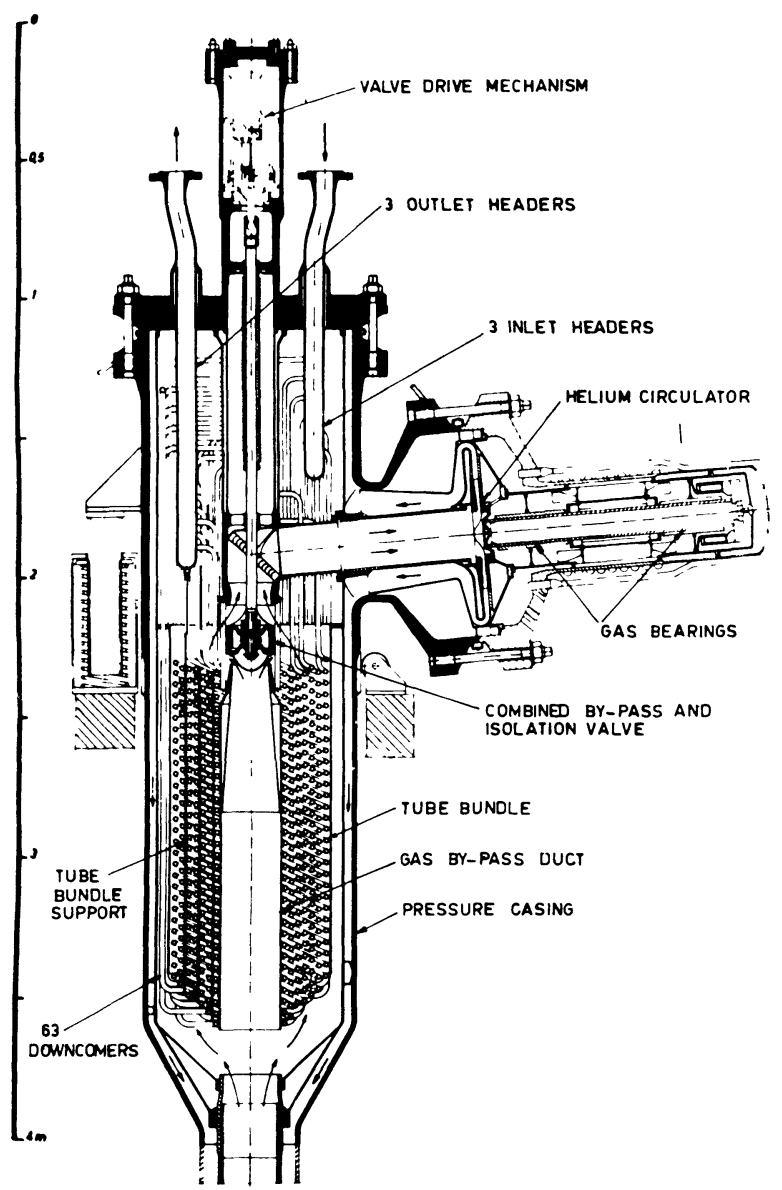

FIG. 7. - Second reactor application. Physical arrangement

When measurements were first attempted, radiation levels in the bypass duct of $a$ few $\mathrm{R} \mathrm{h}^{-1}$ and ambient temperatures of $30^{\circ} \mathrm{C}$ were expected. However, the CdTe performance deteriorated very rapidly when inserted into the bypass duct and investigation showed the maximum radiation level was about $11 \mathrm{R} \mathrm{h}^{-1}$ and the ambient temperature $70^{\circ} \mathrm{C}$. The detector leakage current reached $1.4 \mu \mathrm{A}$ and at this stage the bias resistors would have reduced the detector bias from 200 to 50 Volts. After cooling to room temperature the detector showed no apparent damage and performed quite normally.

A cooling system was improvised using a thermoelectric device with compressed air cooling of the hot junction to enable the detector to operate at $20^{\circ} \mathrm{C}$ in an environment at $70^{\circ} \mathrm{C}$, and a commercial Pile-up Rejector was included in the circuitry, as shown in figure 8 , to handle the high count rate. With this arrangement, spectra were recorded over the full length of the heat exchanger. Three spectra representative of low, medium and high count rates are shown in figure 9. These show resolution respectively of 15,18 and $25 \mathrm{keV}$ at ${ }^{137} \mathrm{Cs}$, the low count rate resolution being very close to the $14 \mathrm{keV}$ measured in the laboratory since the detector was closely coupled to the preamplifier. The highest count rate, measured above a threshold of

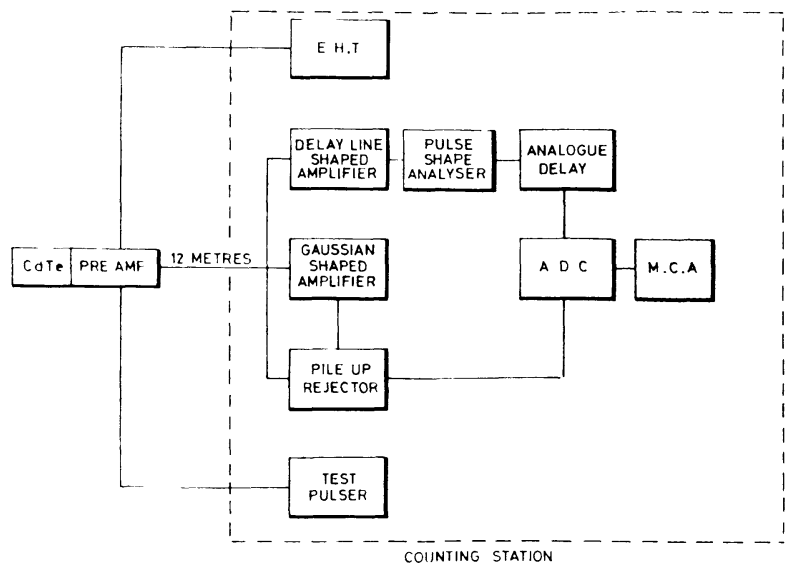

FIG. 8. - Second reactor application. Block electronics.

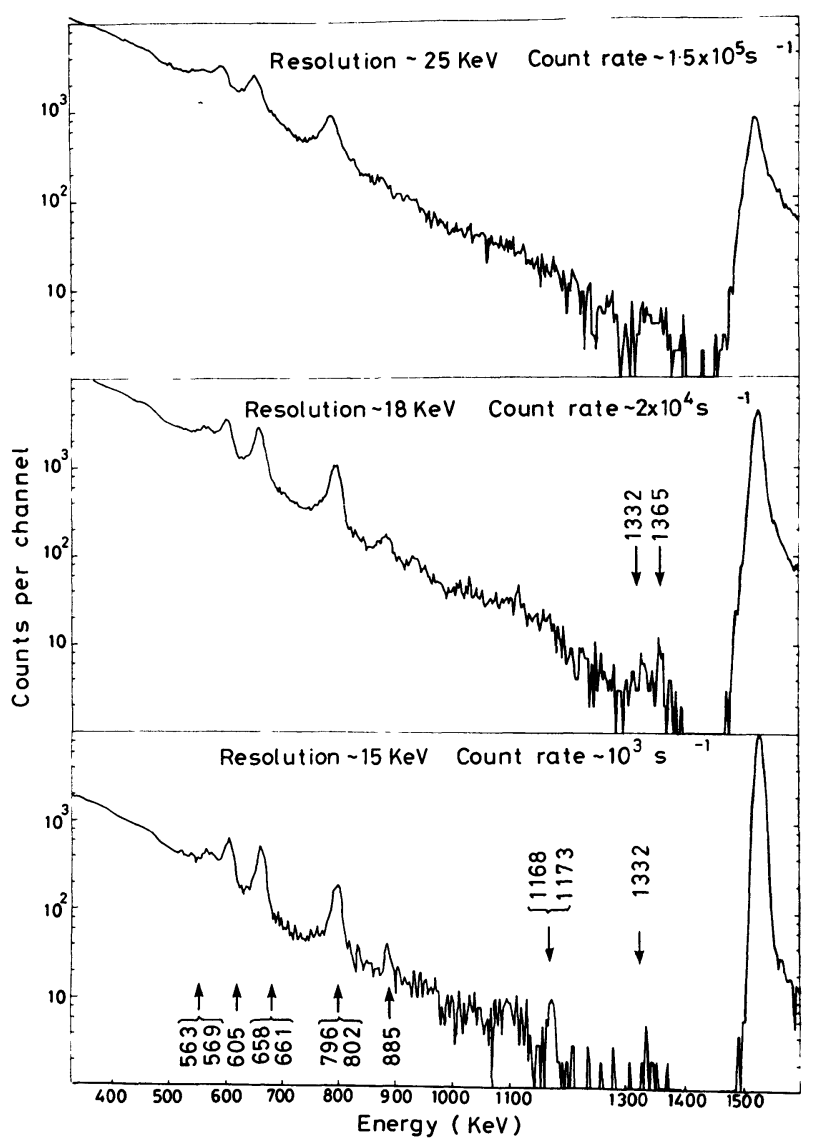

FIG. 9. - Second reactor application. Typical spectra.

about $150 \mathrm{keV}$ was $1.5 \times 10^{5} \mathrm{~s}^{-1}$ and under these conditions only about $1 \%$ of the total counts were reaching the pulse height analyser. The Pile-up Rejector was accepting only $16 \%$ of pulses as uncontaminated by adjacent pulses, while the pulse shape analyser accepted only $7 \%$ of these uncontaminated pulses as having the desired short risetime. A linear plot of a part of the low count-rate spectrum appears in figure 10. 


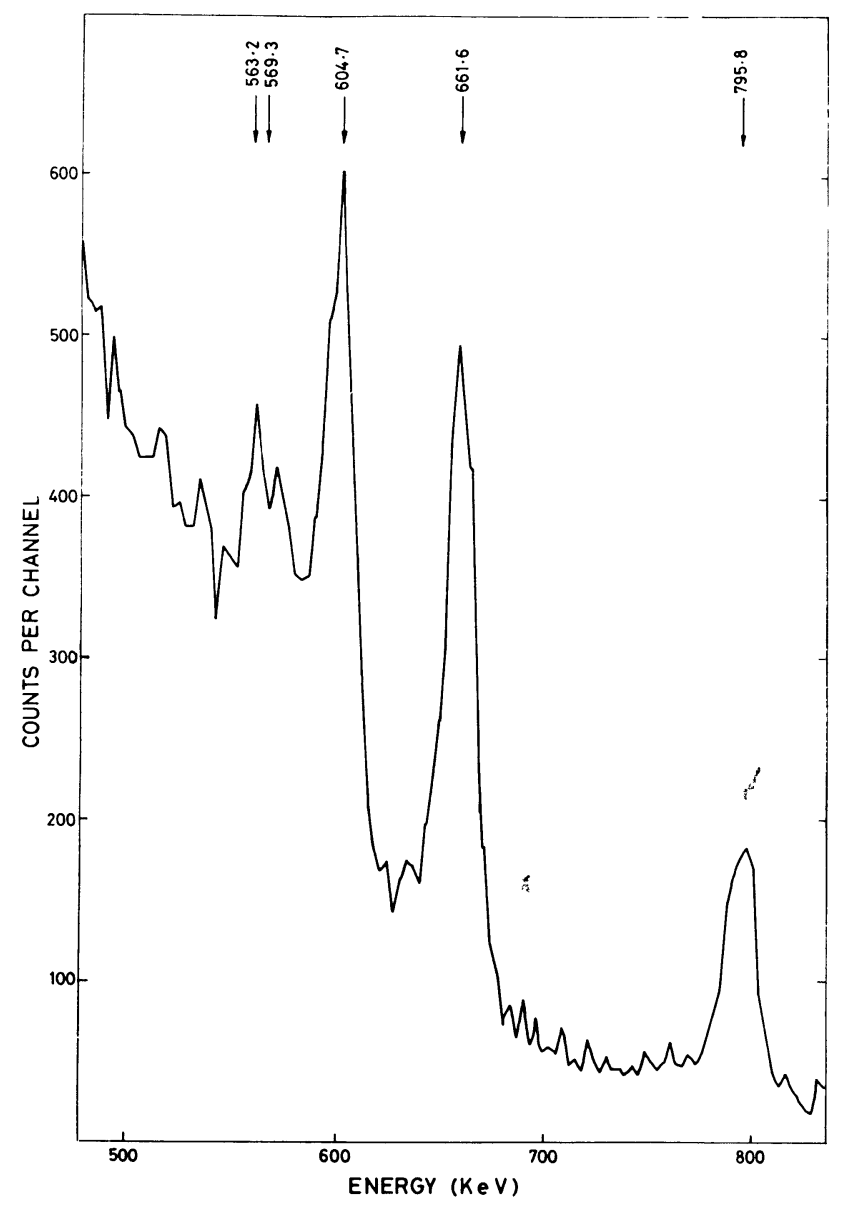

FIG. 10. - Second reactor application. Linear spectrum.
5. Relative merits of CdTe and Ge. - For power reactor applications the small size of currently available CdTe is no restriction since crystals of about $0.5 \mathrm{~cm}^{3}$ are ideal. Because of the larger photo-crosssection the normal efficiency of CdTe would be about five times greater than a $\mathrm{Ge}$ detector of the same size. With P. S. D. the systems efficiency should be about half that of Ge.

The best resolution obtained with CdTe and P. S. D. is $8 \mathrm{keV}$ and this is approaching the $4 \mathrm{keV}$ experienced with $\mathrm{Ge}$ in reactor applications. It enables line energies to be determined to better than $1 \mathrm{keV}$ and is certainly adequate for isotope identification. Techniques for resolving overlapping peaks which were commonplace with $\mathrm{NaI}$ detectors are still required with $\mathrm{Ge}$ detectors and the frequency and difficulty of the problem is not much greater with CdTe since in many situations the isotopes likely to be found are known in advance.

The Peak to Compton ratio of CdTe is potentially its most valuable feature. At $8 \mathrm{keV}$ resolution the Peak to Compton is better than Ge at $2 \mathrm{keV}$. Combined with the reduction in low energy continuum produced by P. S. D., this may make the extraction of low energy peaks easier with CdTe than with $\mathrm{Ge}$ and compensate for the lower net efficiency and poorer resolution.

Acknowledgement. - This paper is published by permission of the Central Electricity Generating Board.

\section{References}

[1] Jones, L. T. and Woolam, P. B., Nucl. Instr. Meth. 124 (1975) 591.

[2] Routti, J. S. and Prussin, S. G., Nucl. Instr. Meth. 72 (1969) 125. 